\title{
The Utility the Platelet-to-Lymphocyte Ratio in Predicting Angiographic Reflow after Primary Percutaneous Coronary Intervention in Patients with Acute ST- Segment Elevation Myocardial Infarction
}

\author{
SAFWAT A.H. EL-HAWARY, M.D.*; MAMDOUH A.M. MAHMOUD, M.D.**; \\ ALI A. RAMZY, M.D.*; MOHAMED S. EL-SAYED, M.D.* and AHMED M.A. IBRAHIM, M.Sc.* \\ The Departments of Cardiology* and Clinical Pathology**, Faculty of Medicine, Al-Azhar University
}

\begin{abstract}
Background: Impaired coronary flow after Primary Percutaneous Coronary Intervention (PPCI) is associated with long term morbidity and mortality in patients with acute STsegment Elevation Myocardial Infarction (STEMI). Recent studies have demonstrated that Platelet-to-Lymphocyte Ratio (PLR) is associated with adverse cardiovascular outcomes. We want to determine the relation between admission (PLR) and angiographic reflow following PPCI.
\end{abstract}

Material and Methods: A total of 72 patients with STEMI(age $55 \pm 10$ years; $91 \%$ men) occurring within 12 hours of the onset of symptoms who underwent PPCI were enrolled. The PLR and other laboratory parameters (CKMB, creatinine, heamoglobin) were measured before Primary Percutaneous Coronary Intervention (PPCI). The patients were divided into 2 groups based on the post-intervention Thrombolysis In Myocardial Infarction (TIMI) flow grade: Normal reflow group (defined as post-intervention TIMI grade 3 flow) and no-reflow group (consisted of both patients with angiographic no-reflow defined as post-intervention TIMI grade 0-1 flow and slow flow defined as post-intervention TIMI grade 2 flow).

Results: There were 31 patients $(22.5 \%)$ in no-reflow group (age $54 \pm 10$ years and $93.5 \%$ male) and 41 patients in normal reflow group (age 55 \pm 11 years and $37 \%$ male). Noreflow group had significantly higher PLR compared to normal reflow group (196-262) versus (139-180), $p=0.009)$. In logistic regression analysis, PLR (Odds Ratio (OR): $1.008,95 \%$ Confidence Interval (CI):1.002-1.014, $p<0.001)$ and were independent predictors of no-reflow after PPCI.

Conclusion: Pre-intervention PLR is a strong and independent predictor of slow flow/no-reflow following PPCI in patients with acute STEMI.

Key Words: Platelet-to-lymphocyte ratio - Post-intervention angiographic reflow - ST-segment elevation myocardial infarction.

Correspondence to: Dr. Ahmed M.A. Ibrahim, E-Mail: ahmed.m.abdelaziiz@.gmail.com

\section{Introduction}

EARLY reperfusion after coronary occlusion in patients with ST-segment Elevation Myocardial Infarction (STEMI) is associated with an improved prognosis [1]

Nevertheless impaired angiographic reflow is still a challenging major issue in the management of the patients with STEMI undergoing Primary Percutaneous Coronary Intervention (PPCI). It is well known that impaired coronary reflow is associated with larger infarct size, worse functional recovery higher incidence of complications, and short and long-term mortality in acute STEMI [2].

Several responsible mechanisms for impaired coronary reflow were identified in experimental models including extravascular compression, microvascular vasoconstriction, aplatelet/leukocyte capillary plugging $[3,4]$. Several studies have shown the relationship between none-reflow and increased inflammatory status.

The Platelet-to-Lymphocyte Ratio (PLR) has recently been investigated as new predictor for major adverse cardiovascular outcomes. It has been found that higher PLR is associated with poor coronary collateral development in stable coronary artery disease and longterm mortality after nonSTEMI $[5,6]$.

\section{Patients and Methods}

This study included 72 patients with first attack of acute ST segment Elevation Myocardial Infarction (STEMI) who underwent primary PCI presenting to the Cardiology Department at Nasr City 
Insurance Hospital and El-Hussien University Hospital during the period from December 2015 to December 2016.

\section{Inclusion criteria:}

Acute STEMI was diagnosed when patient presented by retrosternal squeezing, aching, burning, or even sharp intense and unremitting chest pain for 30-60 minutes that radiates up to the neck, shoulder, jaw or down to the ulnar aspect of the left arm and ECG criteria includes ST segment elevation in two or more contiguous leads greater than $2 \mathrm{~mm}(0.2 \mathrm{mV})$ for males and greater than $1.5 \mathrm{~mm}(0.15 \mathrm{mV})$ in females if in leads V2 and V3 or greater than $1 \mathrm{~mm}(0.1 \mathrm{mV})$ if it is in other ECG leads or Left Bundle Branch Block (LBBB) that is believed to be new [7]

Successful reperfusion was diagnosed by:

- Clinical: Relief from chest pain.

- ECG-ST segment regression $>50 \%$.

- Cardiac enzymes: Early flushing of intra myocytic CPK into systemic circulation and hence early peaking of CPK MB ( $<1$ hours instead of $24 \mathrm{~h})$.

- Reperfusion arrhythmias accelarated idioventricular rhythm.

- Infract related artery patency by coronary angiogram.

\section{Exclusion criteria:}

1- Active infections (pneumonia).

2- Systemic inflammatory disease history.

3- Known malignancy.

4- Major hematologic disorders: Leukemia.

5- Decompancated liver disease.

6- Renal failure.

All patients were subjected to history intake, clinical examination, 12-lead surface ECG, laboratory measurements of $\mathrm{CBC}$, transthoracic echocardiography, cardiac enzymes. For all patients the following data were collected:

1-Demographic data: Age, gender, special habits of medical importance.

2- Clinical patient profiles (coronary risk factors and diagnosis):

A- The major documented risk factorsfor Coronary Artery Disease (CAD) and outcomes of acute coronary syndrome including [8]:

I- Diabetes Mellitus (DM): Defined as history of diabetes regardless of duration of disease, need for antidiabetic agents, fasting plasma glucose $\geq 126 \mathrm{mg} / \mathrm{dl}$ or random blood sugar $>200 \mathrm{mg}$ /dl [9].

II- Hypertension (HTN): Defined as history of hypertension, blood pressure $\geq 140 \mathrm{mmHg}$ systolic and/or $>90 \mathrm{mmHg}$ diastolic on at least 2 occasions or current use of antihypertensive medication [10]

III- Hypercholesterolemia: Defined as total cholesterol >200mg/dl, LDL cholesterol > 130 $\mathrm{mg} / \mathrm{dl}$, HDL cholesterol $<40 \mathrm{mg} / \mathrm{dl}$, triglycerides $>200 \mathrm{mg} / \mathrm{dl}$ or current use of hypolipidemic drugs [11]

$I V$ - Smoking: Defined as smoking within 1 year of admission.

$V$ - Obesity: Defined as BMI $>30 \mathrm{~kg} / \mathrm{m}^{2}[\mathbf{1 2 , 1 3}]$.

$B$ - Chest pain: Duration, character, time before reperfusion, recurrence, radiation.

C-Symptoms of left ventricular dysfunction: Dyspnea, orthopnea, paroxysmal nocturnal dyspnea, fatigue.

D- History of prior myocardial infarction, heart failure and cerebrovascular diseases (defined as ischemic or hemorrhagic stroke or transient ischemic attack).

3- Clinical examination: Full general and local examination done for all patients with special emphasis on: Heart rate, blood pressure and manifestations of heart failure e.g S3 gallop, pulmonary congestion, lower limb edema.

4- Electrocardiographic analysis: Standard 12lead electrocardiograms were recorded at presentation, every 8 hours for 24 hours then daily till discharge and the following data were obtained:

I- Presence of ST segment elevation and it is distribution.

II- Arrhythmia: Brady arrhythmias or tachy arrhythmias.

5- Trans-thoracic echocardiography: It was performed in third day after admission. An echocardiogram may be performed to compare areas of the left ventricle that are contracting normally with those that are not. One of the earliest protective actions of myocardial cells used during limited blood flow is to turn off the energy-requiring mechanism for contraction; this mechanism begins almost immediately after normal blood flow is interrupted. The echocardiogram may be helpful in identifying which portion of the heart is affected by myocadial infarction and which of the coronary arteries is 
most likely to be occluded. Unfortunately, the presence of wall motion abnormalities on the echocardiogram may be the result of an acuteSTEMI or previous (old) MI or other myopathic processes, limiting its overall diagnostic utility [14].

6- Labarotary investigations: Complete blood counts and biochemical values were evaluated from blood samples obtained by antecubital vein puncture upon admission to the emergency department. Common blood counting parameters stored in citrate based anti-coagulated tubes were measured by Beckman/Coulter LH750 analyzer within 5 minutes of sampling.

\section{Complete Blood Count (CBC) [15]:}

- Hemoglobin: (Reference range 13.0-18.0gm/dl).

- The transmittance of light (525nm wavelength) through the lysed WBC solution in the hemoglobin cuvette is compared to the transmittance of the same light through a reagent blank. The system converts this ratio to a HGB value in $\mathrm{g} / \mathrm{dl}$ using a calibration factor.

- Platelets: (Reference range 150-410 (X10 9 /L)).

- Lymphocyte count: (Reference range 1.5-3.5 $\left.\left(\mathrm{X} 10^{9} / \mathrm{L}\right)\right)$.

White blood cell differential: The instrument makes 3 measurements (volume, conductivity and scatter) as each cell passes through the flow cell. The low frequency impedance measurement defines cell volume. The high frequency conductivity measurement indicates the internal conductivity. The light scatter measurement indicates the structure and shape. The AccuGate algorithm is applied to determine different cell populations.

Blood chemistry: Cardiac enzymes and serum creatinine were analyzed using SIEMENS Bayer Advia 1800 Chemistry Analyzer.

Peak values of CK-MB: (Reference range 5-25 $\mathrm{mg} / \mathrm{dl})$.

It will be measured every 8 hours in the first 24 hours then daily till normalization.

Serum creatinine: (Reference range, females: 0.6-1.1mg/dl, males: $0.9-1.3 \mathrm{mg} / \mathrm{dl}$ ) [16].

7- Coronary angiography and intervention procedural details (PPCI):

- Femoral artery puncture was performed in all patients.

- Each coronary was evaluated in at least 2 views.
- The non-culprit vessel was evaluated using a diagnostic catheter.

- The culprit vessel was immediately evaluated by a guiding catheter and site of occlusion identified.

- After assessment other coronaries the culprit vessel was treated by using the following techniques:

- Wiring of the culprit vessel.

- Thrombus aspiration in some patients.

- PTCA using undersized balloon in some patients.

- Stenting with BMS or DES.

- Post deployment PTCA in some patients.

- Deployed stent was assessed for proper deployment, absence of signs of dissection or perforation.

Thrombolysis in Myocardial Infarction (TIMI) flow prior to and after procedure [17]:

- Grade $O$ (no perfusion): There is no antegrade flow beyond the point of occlusion.

- Grade 1 (penetration without perfusion): The contrast material passes beyond the area of obstruction but "hangs up" and fails to opacify the entire coronary bed distal to the obstruction for the duration of the cineangiographic filming sequence.

- Grade 2 (partial perfusion):The contrast material passes across the obstruction and opacifies the coronary bed distal to the obstruction. However, the rate of entry of contrast material into the vessel distal to the obstruction or its rate of clearance from the distal bed (or both) is perceptibly slower than its entry into or clearance from comparable areas not perfused by the previously occluded vessel (e.g. the opposite coronary artery or the coronary bed proximal to the obstruction).

- Grade 3 (complete perfusion): Antegrade flow into the bed distal to the obstruction occurs as promptly as antegrade flow into the bed from the involved bed and is as rapid as clearance from an uninvolved bed in the same vessel or the opposite artery.

A- The TIMI thrombus scale [18].

- Grade 0: No angiographic evidence of thrombus.

- Grade 1: Angiographic features suggestive of thrombus.

- Decreased contrast density.

- Haziness of contrast. 
- Irregular lesion contour.

- A smooth convex meniscus at the site of a total occlusion.

- Suggestive but not firmly diagnostic of thrombus.

- Grade 2: Definite thrombus present in multiple angiographic projections.

- Marked irregular lesion contour with a significant filling defect-the thrombus' greatest dimension is $<1 / 2$ vessel diameter.

- Grade 3: Definite thrombus appears in multiple angiographic views.

- Greatest dimension from $>1 / 2$ to $<2$ vessel diameters.

- Grade 4: Definite large size thrombus present.

- Greatest dimension >2 vessel diameters.

- Grade 5: Definite complete thrombotic occlusion of a vessel.

- A convex margin that stains with contrast, persisting for several cardiac cycles.

\section{Statistical analysis:}

Data were collected, revised, coded and entered to the Statistical Package for Social Science (IBM SPSS) Version 20. Qualitative data were presented as number and percentages while quantitative data were presented as mean, standard deviations and ranges when parametric and median with interquartile ranges (IQR) when non parametric.

The comparison between two groups with qualitative data were done by using chi-square test and/or Fisher exact test was used instead of chisquare test when the expected count in any cell was found less than 5 .

The comparison between two groups regarding quantitative data with parametric distribution was done by using independent $t$-test while data with non parametric distribution was done using MannWhitney test.

The comparison between more than two independent groups regarding quantitative data with parametric distribution was done by using One Way Analysis of Variance (ANOVA) followed by post hoc analysis using LSD test while data with non parametric distribution was done by using Kruskall-Wallis test followed by post hoc analysis using Mann-Whitney test.

Spearman correlation coefficients were used to assess the correlation between two quantitative parameters in the same group.
Receiver Operating Characteristic curve (ROC) was used to assess the best cut off point for platelet/ lymphocyte ratio in prediction of TIMI flow with its Area Under Curve (AUC), sensitivity, specificity, Positive Predictive Value (PPV) and Negative Predictive Value (NPV).

The confidence interval was set to $95 \%$ and the margin of error accepted was set to $5 \%$. So, the $p$ value was considered significant as the following: $\bullet p>0.05$ : Non significant.

$\bullet p<0.05$ : Significant.

$\bullet p<0.01$ : Highly significant.

\section{Results}

From December 2015 to November 2016, a totally of 72 consecutive patients with STEMI occurring within 12 hours of the onset of symptoms who underwent PPCI in our institution were enrolled into the study to investigate the usefulness of PLR in predicting angiographic reflow following PPCI in acute STEMI.

The patients were divided into 2 groups based on the post-intervention Thrombolysis in Myocardial Infarction (TIMI) flow grade: Normal-flow group and none-reflow group. Normal-flow was defined as post-intervention TIMI grade 3 flow. None-reflow group consisted of both patients with angiographic no-reflow (defined as post-intervention TIMI grade $0-1$ flow) and slow flow (defined as post-intervention TIMI grade 2 flow). Angiographic no-reflow can be defined as Thrombolysis In Myocardial Infarction (TIMI) flow less than grade 3 .

Baseline demographic and clinical characteristics of study population:

The study included 72 patients, the mean age was $55.39 \pm 10.70 \mathrm{yrs}$., there were 66 males $(91.7 \%)$, 33 diabetic patients $(45.8 \%), 36$ patients had hypertension (50\%), 43 smokers (59.7\%), 25 patients were dyslipidemic (34.7\%), 20 patients had positive family history $(27.8 \%)$ (Tables 1,2$)$.

Comparing patients with normal -flow and noreflow groups:

There were 31 patients $(29.0 \%)$ in no-reflow group (mean age 54.87 \pm 10.57 and $29(93.5 \%)$ males) and 41 patients in normal-flow group (mean age $55.78 \pm 10.92$ and $90.2 \%$ male). There was no statistically significant differences between both group regarding age, sex (Table 4). 
Baseline clinical characteristics in relation to normal -flow and none-reflow between 2 groups:

There was a large number of diabetic patient in the none reflow group $(n o=20,64.5 \%$ versus 13 patients $(31 \%)$ in normal-flow group $p=0.006)$.

No significant differences regarding hypertension,smoking, hyperlipidemia and family history were observed between groups (Table 5).

Comparison between reflow group and non reflow group regarding ejection fraction: A statistically significant diffferance was found between both groups regarding ejection fraction $(p$-value $=$ 0.001) (Table 6).

Correlation of platelets/lymphocytes ratio with variables:

There was no statistically significant correlation between $\mathrm{P} / \mathrm{L}$ ratio and age, sex, hypertension, smoking, hyperlipidemia, family history were observed. There was significant correlation between $\mathrm{P} / \mathrm{L}$ ratio and Platelet count, Lymphocytic count and no significant correlation between $\mathrm{P} / \mathrm{L}$ ratio and other laboratory findings (Table 7).

Receiver operating characteristic curve analysis of Platelet-to-Lymphocyte Ratio data for angiographic slow flow/no-reflow.

The area under the ROC curve for PLR was 0.680 , and a PLR of $\leq 187.86$ predicted none-reflow with a sensitivity of $80.49 \%$ and specificity of 58.06 Fig. (3).

There was statistically significant association found between $\mathrm{P} / \mathrm{L}$ ratio and TIMI flow with $p$ value $<0.05$ (Table 8 ).

Table (1): Age and sex distribution among the studied patients.

\begin{tabular}{cl}
\hline & \multicolumn{1}{c}{$\mathrm{N}=72$} \\
\hline Age year: & \\
Mean \pm SD & $55.39 \pm 10.70$ \\
Range & $32-87$ \\
Sex: & \\
Female & $6(8.3 \%)$ \\
Male & $66(91.7 \%)$ \\
\hline
\end{tabular}

Table (2): Risk factors among the studied patients.

\begin{tabular}{lll}
\hline & $\mathrm{N}$ & $\%$ \\
\hline DM & 33 & 45.8 \\
HTN & 36 & 50 \\
Smoking & 43 & 59.7 \\
Dyslipidemia & 25 & 34.7 \\
Family history & 20 & 27.8 \\
\hline DM: Diabeites Mellitus. & HTN: Hypertension.
\end{tabular}

Table (3): Shows the laboratory findings of study population.

\begin{tabular}{|c|c|c|c|c|}
\hline & \multicolumn{4}{|c|}{ No. $=72$} \\
\hline \multicolumn{5}{|c|}{$C K M B(m g / d l):$} \\
\hline \multicolumn{2}{|c|}{ Median (IQR) } & \multicolumn{3}{|c|}{$97(45.5-270)$} \\
\hline Range & & \multicolumn{3}{|c|}{$15-827$} \\
\hline \multicolumn{5}{|c|}{ Serum creatinine $(m g / d l)$ : } \\
\hline \multicolumn{2}{|l|}{ Mean \pm SD } & \multicolumn{3}{|c|}{$1.15 \pm 0.37$} \\
\hline Range & & \multicolumn{3}{|c|}{$0.5-2.9$} \\
\hline \multicolumn{5}{|l|}{ Platelet count: } \\
\hline \multicolumn{2}{|l|}{ Mean \pm SD } & \multicolumn{3}{|c|}{$264.44 \pm 80.65$} \\
\hline Range & & \multicolumn{3}{|c|}{$128-519$} \\
\hline \multicolumn{5}{|c|}{ Lymphocytic count: } \\
\hline Mean \pm SD & & \multicolumn{3}{|c|}{$1.82 \pm 0.91$} \\
\hline Range & & \multicolumn{3}{|c|}{$0.6-5.4$} \\
\hline \multicolumn{5}{|l|}{$P / L$ : } \\
\hline \multirow{2}{*}{\multicolumn{2}{|c|}{$\begin{array}{l}\text { Median (IQR) } \\
\text { Range }\end{array}$}} & \multicolumn{3}{|c|}{$162.63(114.34-226.86)$} \\
\hline & & 41.5 & $0-442.50$ & \\
\hline \multicolumn{5}{|l|}{$H B(m g / d l):$} \\
\hline \multirow{2}{*}{\multicolumn{2}{|c|}{$\begin{array}{l}\text { Mean } \pm \text { SD } \\
\text { Range }\end{array}$}} & \multicolumn{3}{|c|}{$12.97 \pm 1.65$} \\
\hline & & \multicolumn{3}{|l|}{$8-18$} \\
\hline \multicolumn{5}{|c|}{$\begin{array}{l}\text { CKMB : Creatinen Kinase Myocardial Bortion }(\mathrm{mg} / \mathrm{dl}) \text {. } \\
\text { P/L ratio : Platelet to lymphocyte ratio. } \\
\text { HB : Heamoglobin }(\mathrm{mg} / \mathrm{dl}) \text {. }\end{array}$} \\
\hline \multicolumn{5}{|c|}{$\begin{array}{l}\text { Table (4): Comparing patients with normal-flow and no- } \\
\text { reflow groups regarding age and sex. }\end{array}$} \\
\hline & \multirow{2}{*}{$\begin{array}{l}\text { Reflow } \\
\mathrm{N}=41\end{array}$} & \multirow{2}{*}{$\begin{array}{l}\text { No reflow } \\
\mathrm{N}=31\end{array}$} & \multicolumn{2}{|c|}{ Independent $t$-test } \\
\hline & & & $t / \chi^{2} *$ & $p$-value \\
\hline \multicolumn{5}{|l|}{ Age year: } \\
\hline Mean \pm SD & $55.78 \pm 10.92$ & $54.87 \pm 10.57$ & 0.355 & 0.724 \\
\hline Range & $35-87$ & $32-80$ & & \\
\hline \multicolumn{5}{|l|}{ Sex: } \\
\hline Female & $4 \quad(9.8 \%)$ & $2(6.5 \%)$ & $0.252 *$ & 0.615 \\
\hline Male & $37(90.2 \%)$ & $29(93.5 \%)$ & & \\
\hline
\end{tabular}

Table (5): Comparing patient with normal reflow and noreflow groups regarding risk factor.

\begin{tabular}{lcccccc}
\hline \multirow{2}{*}{ Risk factor } & \multicolumn{2}{c}{ Reflow } & \multicolumn{2}{c}{ No reflow } & \multicolumn{2}{c}{ Chi-square test } \\
\cline { 2 - 7 } & $\mathrm{N}$ & $\%$ & $\mathrm{~N}$ & $\%$ & $\chi^{2}$ & $p$-value \\
\hline DM & 13 & 31.7 & 20 & 64.5 & 7.654 & 0.006 \\
HTN & 18 & 43.9 & 18 & 58.1 & 1.416 & 0.234 \\
Smoking & 21 & 51.2 & 22 & 71.0 & 2.862 & 0.091 \\
Dyslipidemia & 12 & 29.3 & 13 & 41.9 & 1.250 & 1.250 \\
Family history & 9 & 22.0 & 11 & 35.5 & 1.611 & 0.204 \\
\hline DM: Diabeites Mellitus. & \multicolumn{4}{c}{ HTN: Hypertension. }
\end{tabular}

Table (6): Comparison between reflow group and non reflow group regarding ejection fraction.

\begin{tabular}{|c|c|c|c|c|}
\hline \multirow{2}{*}{$\mathrm{ECHO} / \mathrm{EF}$} & \multirow{2}{*}{$\begin{array}{c}\text { Reflow } \\
\mathrm{N}=41\end{array}$} & \multirow{2}{*}{$\begin{array}{c}\text { No reflow } \\
\mathrm{N}=31\end{array}$} & \multicolumn{2}{|c|}{ Independent $t$-test } \\
\hline & & & $t$ & $p$-value \\
\hline Mean \pm SD & $52.49 \pm 8.1$ & $45.16 \pm 9.85$ & 3.467 & 0.001 \\
\hline Range & $36-69$ & $25-61$ & & \\
\hline
\end{tabular}


Table (7): Correlation between platelets/lymphocytes ratio and the other studied parameters.

\begin{tabular}{lcc}
\hline & \multicolumn{2}{c}{$\mathrm{P} / \mathrm{L}$} \\
\cline { 2 - 3 } & \multicolumn{1}{c}{$r$} & $p$-value \\
\hline Age & 0.170 & 0.154 \\
CKMB & 0.136 & 0.254 \\
Creatinin & 0.138 & 0.246 \\
Platelet count & $0.554^{* *}$ & 0.001 \\
Lymphocytic count & $-0.685^{*} *$ & 0.001 \\
HB & -0.166 & 0.170 \\
ECHO/EF & -0.160 & 0.180
\end{tabular}

CKMB : Creatinen Kinase Myocardial Bortion (mg/dl).

$\mathrm{P} / \mathrm{L}$ (ratio) : Platelet to lymphocyte ratio. ECHO: Echocardiography.

HB : Heamoglobin (mg/dl). EF : Ejection Fraction.

Table (8): Logistic regression analysis for the association between TIMI flow and $\mathrm{P} / \mathrm{L}$ ratio.

\begin{tabular}{|c|c|c|c|c|c|c|}
\hline & \multirow[t]{2}{*}{ B } & \multirow{2}{*}{ S.E. } & \multirow{2}{*}{ Wald } & \multirow{2}{*}{$\begin{array}{c}p- \\
\text { value }\end{array}$} & \multirow{2}{*}{$\begin{array}{c}\text { Odds } \\
\text { ratio } \\
(\mathrm{OR})\end{array}$} & $\begin{array}{c}\text { 95\% C.I. } \\
\text { for OR }\end{array}$ \\
\hline & & & & & & Lower Upper \\
\hline $\mathrm{P} / \mathrm{L}$ & 0.008 & 0.003 & 6.146 & 0.013 & 1.008 & $1.002 \quad 1.014$ \\
\hline Constant & -1.635 & 0.597 & 7.493 & 0.006 & 0.195 & \\
\hline
\end{tabular}

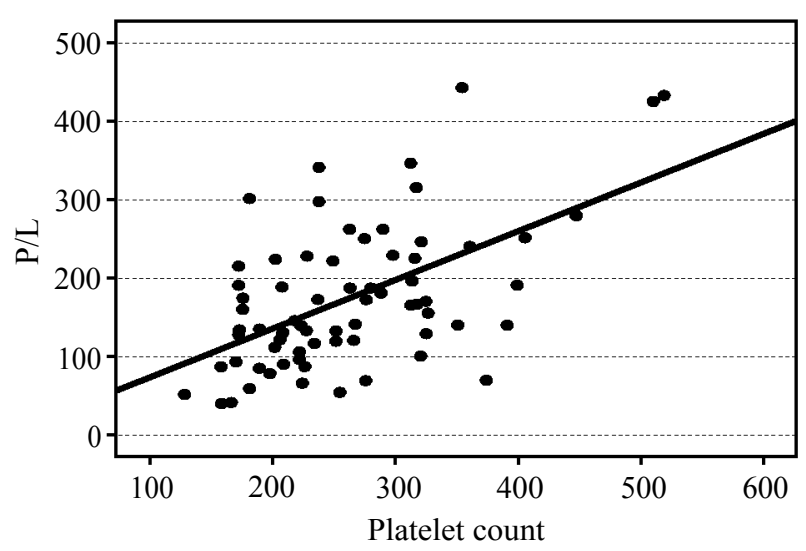

Fig. (1): Correlation between platelets/lymphocytes ratio and platelet count.

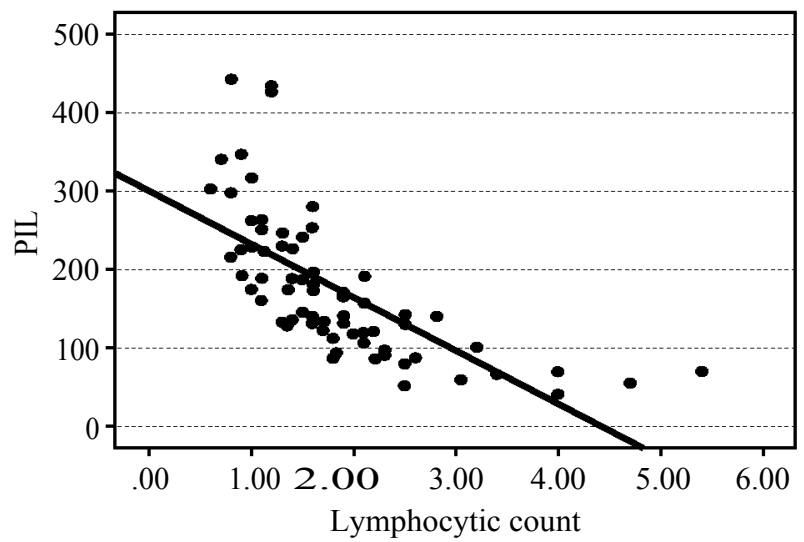

Fig. (2): Correlation between platelets/lymphocytes ratio and lymphocytic count.

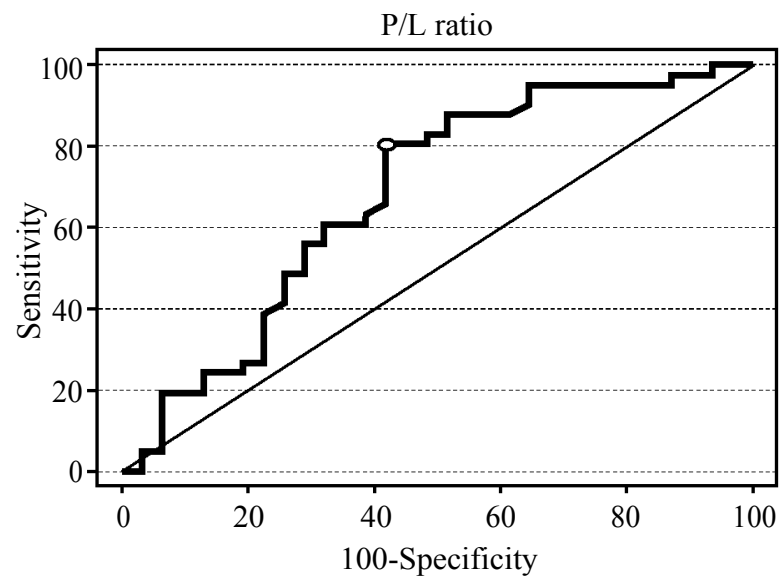

Fig. (3): Receiver Operating Characteristic Curve (ROC) for platelets/lymphocytes ratio in prediction of TIMI flow.

\begin{tabular}{lccccc}
\hline Cut off point & AUC & Sensitivity & Specificity & $+\mathrm{PV}$ & $-\mathrm{PV}$ \\
\hline 187.86 & 0.680 & 80.49 & 58.06 & 71.7 & 69.2 \\
\hline
\end{tabular}

\section{Discussion}

Rapid restoration of infarct-related arterial flow is associated with improved ventricular performance and lower mortality in patients with STEMI [1]. However, poor post-interventional reflow may limit the benefits of recanalization of the culprit vessel [19]. Impaired angiographic reflow is strongly correlated with morbidity and mortality in acute STEMI [20,21]. It is associated with larger infarct size, worse functional recovery, and higher incidence of complications. The pathophysiology of none-reflow has not been fully explained and its etiology appears to be multifactorial. These factors include ischemic endothelial damage, microvascular leukocytes and platelet plugging and complex interactions between leukocytes and platelets induced by the inflammatory process [22]. Several studies $h$ ave shown the relationship between none-reflow and increased inflammatory status.

This study was done to demonstrate that higher value of PLR was found in none-reflow group when compared to normal reflow group in patients with STEMI who underwent PPCI. This finding may contribute to explain the possible underlying mechanisms of poor post intervention flow.

This study demonstrated two major findings in patients with acute STEMI undergoing PPCI. First, the PLR on admission was significantly higher in post-intervention none-reflow group. Second, PLR can be considered as indicator of none-reflow following PPCI in patients with STEMI. 
Increased platelet counts may reflect underlying inflammation as several inflammatory mediators stimulate megakaryocytic proliferation and produce relative thrombocytosis. Moreover, studies have shown that patients with coronary atherosclerosis have elevated levels of platelet monocyte aggregates in their bloodstream, which correlate with plaque stability [22]. On the other side, lymphocytes represent a quiescent and controlling inflammatory pathway. In cancer patients, lymphocyte was responsible on the programmed cell death, apoptosis [23]

In our study, we showed that PLR was one of the factors for post-intervention none-reflow in acute STEMI. We speculate two factors that explain the superiority of PLR to either individual lymphocyte or platelet counts. First, the stability of PLR compared to the absolute platelet or lymphocyte counts, which could be altered by many physiological and pathological conditions. Secondly and most importantly, the PLR represent two inversely related predictors and immune pathways.

Previous studies have demonstrated that higher platelet and lower lymphocyte counts were associated with adverse cardiovascular outcomes [24,25]

Recently, study done by Azab et al., [26] showed that higher value of PLR as a marker of long-term mortality in patients with non-STEMI. This was an observational study with a total 619 NSTEMI patients admitted to a tertiary center between 2004 and 2006. Patients were stratified into equal tertiles according to their admission PLR. The primary outcome, 4-year all-cause mortality, was compared among the PLR tertiles. The first, second and third PLR tertiles were PLR $<118.4,118.4 \leq \mathrm{PLR} \leq 176$, and PLR > 176, respectively) included 206, 206 and 207 patients, respectively. There was significant higher 4-year all-cause mortality in the higher PLR tertiles (the mortalities were 17, 23 and $42 \%$ for the first, second and third PLR tertiles respectively, $p<0.0001)$.

The study by Oylumlu et al., [27] found that PLR is a risk variable for in-hospital mortality in patient with ACS. This study was single-centered and observational study. In total, 587 patients with a mean age of $61.8 \pm 13.1$ years $(68.4 \%$ male $)$ were enrolled in the study. Patients were divided into 3 tertiles based on PLR levels. In-hospital mortality was significantly higher among patients in the upper PLR tertile when compared with the middle and lower PLR tertile groups (29 $(14.8 \%)$ vs. 17 $(8.7 \%)$ and $2(1.0 \%) ; p^{<0.001) . ~}$
Another study by Oylumlu et al., [27]. Also demonstrated that high pre-procedural PLR is a significant and independent predictor of stent thrombosis in patients with acute STEMI. They retrospectively analyzed the clinical, hematologic, and angiographic data of total 201 patients (mean age $59.8 \pm 13.1$ years, 3 out of 4 were males) who had undergone PCI for acute STEMI and a further control coronary angiography. 54 patients of them were diagnosed as stent thrombosis and formed the patient group and 147 patients matched with patient group in terms of age, gender, traditional coronary risk factors, stent implantation procedure, and stent type and length formed the control group in whom the stent implanted during primary PCI was found patent in the repeat coronary angiography. The pre-procedural PLR was significantly higher in patients with stent thrombosis compared to patients without stent thrombosis ( $176 \pm 68 \mathrm{vs}$. $135 \pm 62 ; p<0.001)$.

The relationship between white blood cell count and increased cardiovascular risk is well established. While high neutrophil counts reflect the inflammatory response, low lymphocyte counts reflect poor general health and physiologic stress [28].

Furthermore, Sünbül et al., [29] found that the PLR was a significant predictor of non-dipper status in patients with hypertension. The study included 166 patients with hypertension. Eightythree patients (40 male, mean age: $49.1 \pm 10.5$ years) had dipper hypertension, while 83 patients (41 male, mean age: $52.3 \pm 12.7$ years) had non-dipper hypertension. Baseline demographic characteristics were similar in both groups. Patients with nondipper hypertension had significantly higher NLR compared to dipper hypertension $(2.3 \pm 0.9$ versus $1.8 \pm 0.5, p<0.001)$. Patients with non-dipper hypertension had significantly higher PLR compared to dipper hypertension $(117.7 \pm 35.2$ versus $100.9 \pm 30.5$, $p=0.001$ ).

Gary et al., [30] revealed that increased PLR is significantly associated with patients at high risk for critical limb ischemia. They evaluated 2121 Peripheral Arterial Occlusive Disease (PAOD) patients treated at their institution from 2005 to 2010. PLR was calculated and the cohort was categorized into tertiles according to the PLR. As an optimal cut-off value, a PLR of 150 was identified. Two groups were categorized, one containing 1228 patients (PLR $\leq 150)$ and a second group with 893 patients (PLR >150). CLI was more frequent in PLR $>150$ patients $(410(45.9 \%))$ compared to PLR $\leq 150$ patients $(270(22.0 \%))(p<0.001)$. 
In addition to its prognostic significance, the PLR has also been demonstrated in patients with various cancers in a relatively recent study in patients with small cell carcinoma of the esophagus, PLR was proven to be superior to NLR in terms of relapsefree survival and overall survival [31]

In our study similar outcomes, regarding PLR as an indicator of none-reflow following PPCI in patients with STEMI, were obtained in concordance with Kurtul et al., study.

Kurtul et al., [32] demonstrated that PLR on admission $\geq 126$ predicted the angiographic nonereflow with an $73 \%$ sensitivity and $71 \%$ specificity and PLR is a significant and independent predictor of none-reflow following PPCI. A total of 520 patients with acute STEMI (age 60 \pm 13 years; $74 \%$ men) occurring within 12 hours of the onset of symptoms who underwent PPCI were enrolled. The PLR and other laboratory parameters were measured before PPCI. The patients were divided into 2 groups based on the post-intervention Thrombolysis in Myocardial Infarction (TIMI) flow grade: Normal reflow group (defined as post-intervention TIMI grade 3 flow) and none-reflow group (consisted of both patients with angiographic no-reflow defined as post-intervention TIMI grade 0-1 flow and slow flow defined as post-intervention TIMI grade 2 flow).

There were 117 patients $(22.5 \%)$ in none-reflow group (age $68 \pm 13$ and $77 \%$ male) and 403 patients in normal reflow group (age $58 \pm 12$ and $63 \%$ male). None-reflow group had significantly higher PLR compared to normal reflow group $(219 \pm 79$ versus $115 \pm 59, p<0.001)$. In logistic regression analysis, PLR (Odds Ratio (OR): 1.818, 95\% Confidence Interval (CI): $1.713-1.980, p<0.001)$ and total stent length (OR: 1.052, CI: 1.019-1.086, $p=0.002$ ) were independent predictors of none-reflow after PPCI.

In kurtul et al., study, patients with none-reflow were significantly older with higher prevalence of male gender, diabetes mellitus, but lower LVEF and lower smoking compared to those in the normal-reflow. No significant differences regarding hyperlipidemia and family history were observed between groups in both studies.

However, in our study, we demonstrated that PLR on admission $>187.86$ predicted the angiographic none-reflow with $80.49 \%$ sensitivity and $58.06 \%$ specificity. A total of 72 patients with acute STEMI (age $55 \pm 10$ years; $91 \%$ men) occurring within 12 hours of the onset of symptoms who underwent PPCI were enrolled. The PLR and other laboratory parameters were measured before PPCI.
The patients were divided into 2 groups based on the post-intervention Thrombolysis in Myocardial Infarction (TIMI) flow grade: Normal reflow group (defined as post-intervention TIMI grade 3 flow) and none-reflow group (consisted of both patients with angiographic no-reflow defined as postintervention TIMI grade 0-1 flow and slow flow defined as post-intervention TIMI grade 2 flow).

There were 31 patients $(22.5 \%)$ in none-reflow group (age $54 \pm 10$ and $93.5 \%$ male) and 41 patients in normal reflow group (age $55 \pm 11$ and $37 \%$ male). None-reflow group had significantly higher PLR compared to normal reflow group (196-262) versus (139-180), $p=0.009)$. In logistic regression analysis, PLR (Odds Ratio (OR): 1.008, 95\% Confidence Interval (CI): 1.002-1.014, $p<0.001)$ and were independent predictors of none-reflow after PPCI.

In Kurtul et al., study, patients with none-reflow were significantly older with higher prevalence of female gender, diabetes mellitus, but lower LVEF and lower smoking compared to those in the normal-reflow. No significant differences regarding hyperlipidemia,family history and hypertension were observed between groups in both studies.

However in our study no significant difference were observed between groups regarding male gender, and smoking except in diabetes mellitus. There was a large number of diabetic patient in the none reflow group (no=20, 64.5\% versus 13 patients $(31 \%)$ in normal-reflow group $p=0.006$.

Ejection fraction was significantly lower in none-reflow group (mean $45.16 \pm 9.85$ versus $52.49 \pm$ 8.1 in reflow group, $p<0.001)$.

Some of the possible interactions (age-PLR; gender-PLR; creatinine-PLR; and diabetes-PLRhypertension-PLR, CK MB-PLR) were also assessed, however they found to be non-significant in both studies.

\section{Conclusion:}

- PLR on admission was significantly higher in post-intervention none-reflow group.

- PLR on admission $>187.86$ predicted the angiographic none-reflow with 80.49 sensitivity and $58.06 \%$ specificity.

- Diabetic patient with increased PLR are at higher risk of none-reflow.

- Patients with lower ejaction fraction after STEMI with increased PLR are at higher risk of nonereflow. 
- Different from other inflammatory markers and assays, PLR is an inexpensive and readily available biomarker that may be useful as predictor of none-reflow following PPCI in patients with STEMI.

\section{References}

1- The Gusto Angiographic Investigators. The effect of tissue plasminogen activator, streptokinase, or both on coronaryartery patency, ventricular function, and survival after acute myocardial infarction. N. Engl. J. Med., 329: 161522, 1993.

2- STONE G.W., PETERSON M.A., et al.: Impact of normalized myocardial perfusion after successful angioplasty in acute myocardial infarction. J. Am. Coll. Cardiol., 39: 591-7, 2002.

3- REZKALLA S.H. and KLONER R.A.: Slow or no reflow. Circulation, 105: 656-62, 2002.

4- REZKALLA S.H. and KLONER R.A.: Coronary slow or no reflow: From the experimental laboratory to the cardiac catheterization laboratory. Catheter. Cardiovasc. Interv., 72: 950957, 2008.

5- AÇAR G., KALKAN M.E., et al.: The Relation of PlateletLymphocyte Ratio and Coronary Collateral Circulation in Patients With Stable Angina Pectoris and Chronic Total Occlusion. Clin. Appl. Thromb. Hemost. Epub., 18, 2013.

6- AZAB B., SHAH N., et al.: Value of platelet/lymphocyte ratio as a predictor of all-cause mortality after non-STelevation myocardial infarction. J. Thromb. Thrombolysis, 34: 326-34, 2012.

7- MANDELZWEIG L., BATTLER A., BOYKO V., et al.: The second Euro Heart Survey on acute coronary syndromes: Characteristics, treatment, and outcome of patients with ACS in Europe and the Mediterranean Basin in 2004, Eur. Heart J., 27: 2285-93, 2006.

8- NYBOE J., JENSEN G., APPLEYARD M. and SCHNOHR P.: "Risk factors for acute myocardial infarction in Copenhagen. I: Hereditary, educational and socioeconomic factors. Copenhagen City Heart Study." Euro Heart J., 10 (10): 910-6, 1989.

10- KAPLAN N.M. and OPIE L.H.: Controversies in hypertension. Lancet, 367: 168, 2006.

11- PEARSON T.A., MENSAH G.A., ALEXANDER R.W., ANDERSON J.L., CANNON R.O. $3^{\text {rd }}$, CRIQUI M., FADL Y.Y., FORTMANN S.P., HONG Y., MYERS G.L., RIFAI N., SMITH S.C. Jr., TAUBERT K., TRACY R.P. and VINICOR F.: Centers for Disease Control and Prevention; American Heart Association, 2003.

12- JANKET S.J., BAIRD A.E., CHUANG S.K. and JONES J.A.: "Meta-analysis of periodontal disease and risk of coronary heart disease and stroke." Oral. Surg. Oral. Med. Oral. Pathol. Oral. Radiol. Endod., 95 (5): 559-69, 2003.

13- KHADER Y.S., RICE J., JOHN L. and ABUEITA O.: "Oral contraceptives use and the risk of myocardial infarction: A meta-analysis. "Contraception, 68 (1): 117, 2003.

14- CHEITLIN M.D., ARMSTRONG W.F., AURIGEMMA G.P., et al.: ACC/AHA/ASE 2003 guideline update for the clinical application of echocardiography: Summary article: A report of the American College of Cardiology/ American Heart Association Task Force on Practice Guidelines (ACC/AHA/ASE Committee to Update the 1997 Guidelines for the Clinical Application of Echocardiography). Circulation, 108: 1146, 2003.

15- VAJPAYEE N., GRAHAM S.S. and BEM S.: Basic examination of blood and bone marrow. In: McPherson R.A., Pincus M.R., eds. Henry's Clinical Diagnosis and Management by Laboratory Methods. 22 nd ed. St Louis, MO: Elsevier, Chap. 30, 2017.

16- STEVENS L.A., CORESH J., GREENE T. and LEVEY A.S.: Assessing kidney function-measured and estimated glomerular filtration rate. N. Engl. J. Med., 354: $2473-$ 83, 2006.

17- DAVID A. MORROW, et al.: TIMI Risk Score for STElevation Myocardial Infarction: A Convenient, Bedside, Clinical Score for Risk Assessment at Presentation: An Intravenous nPA for Treatment of Infarcting Myocardium Early II Trial Substudy Circulation, 102: 2031-7, 2002.

18- GIBSON C.M., De LEMOS J.A., et al.: Combination therapy with abciximab reduces angiographically evident thrombus in acute myocardial infarction: A TIMI 14 substudy. Circulation, 103: 2550-4, 2001.

19- KAYA M.G., ARSLAN F., et al.: Myocardial blush grade: A predictor for major adverse cardiac events after primary PTCA with stent implantation for acute myocardial infarction. Acta Cardiol., 62: 445-51, 2007.

20- CELIK T., IYISOY A., et al.: The impact of admission C-reactive protein levels on the development of slow or no reflow after primary PCI in patients with acute myocardial infarction: The role of inflammation. Int. J. Cardiol., 136: 86-8, 2009.

21- BROSH D., ASSALI A.R., et al.: Effect of slow or no reflow during primary percutaneous coronary intervention for acute myocardial infarction on six-month mortality. Am. J. Cardiol., 99: 442-5, 2007.

22- LINDEN M.D., FURMAN M.I., et al.: Indices of platelet activation and the stability of coronary artery disease. J. Thromb. Haemost., 5: 761-76, 2007.

23- NIEDERHUBER J.E.: Cancer Vaccines: The Molecular Basis for T Cell Killing of Tumor Cells. Oncologist., 2: 280-3, 1997.

24- NDREPEPA G., TIROCH K., et al.: 5-year prognostic value of slow or no reflow after percutaneous coronary intervention in patients with acute myocardial infarction. J. Am. Coll. Cardiol., 55: 2383-9, 2010.

25- NIKOLSKY E., GRINES C.L., et al.: Impact of baseline platelet count in patients undergoing primary percutaneous coronary intervention in acute myocardial infarction (from the CADILLAC trial). Am. J. Cardiol., 99: 1055-61, 2007.

26- AZAB B., SHAH N., et al.: Value of platelet/lymphocyte ratio as a predictor of all-cause mortality after non-STelevation myocardial infarction. J. Thromb. Thrombolysis, 34: 326-34, 2012.

27- OYLUMLU1 M., Y1LD1Z A., et al.: Usefulness of PlateletLymphocyte Ratio to Predict Stent Thrombosis in Patients 
with ST Elevation Myocardial Infarction, Kosuyolu Heart Journal, 17 (2): 81-5, 2014.

28- OMMEN S.R., GIBBONS R.J., et al.: Usefulness of the lymphocyte concentration as a prognostic marker in coronary artery disease. Am. J. Cardiol., 79: 812-4, 1997.

29- SÜNBÜL M., GERIN F., et al.: Neutrophil to lymphocyte and platelet to lymphocyte ratio in patients with dipper versus non-dipper hypertension. Clin. Exp. Hypertens, 20. (Epub ahead of print), 2013.

30- GARY T., PICHLER M., et al.: Platelet-to-lymphocyte ratio: A novel marker for critical limb ischemia in periph- eral arterial occlusive disease patients. PLoS One, 8: e67688, 2013.

31- FENG J.F., HUANG Y., et al.: Clinical significance of preoperative neutrophil lymphocyte ratio versus platelet lymphocyte ratio in patients with small cell carcinoma of the esophagus. Scientific World Journal, 2013: 504365, 2013.

32- KURTUL A., YARLIOGLUES M., et al.: Usefulness of the Platelet-to-Lymphocyte Ratio in Predicting Angiographic Reflow Following Primary Percutaneous Coronary Intervention in Patients with Acute ST- Segment Elevation Myocardial Infarction, Doi: 10.1016/j.amjcard, 2014.

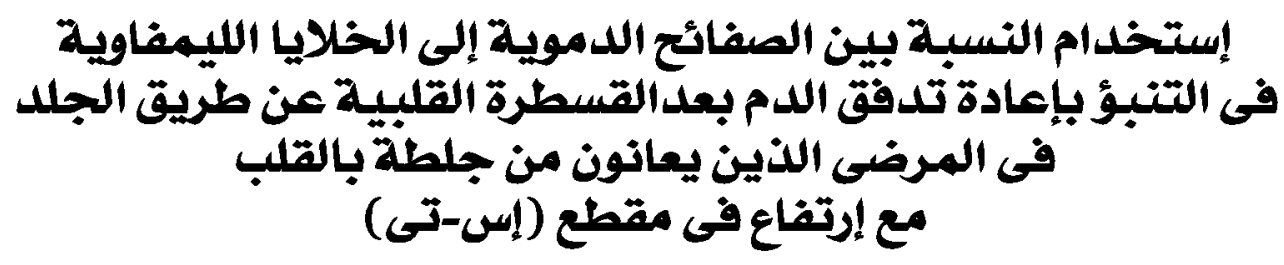

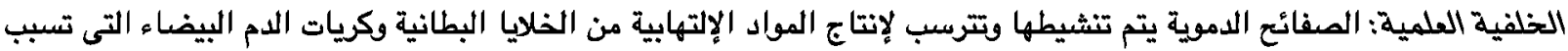

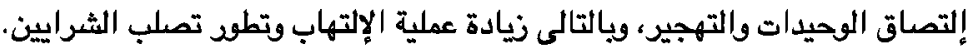

موت جزء من عضلة القلب المفاجئ والحاد عادة ما يحدث نتيجة لإنسداد الثريان التاجى بسبب مضاعفات تصلب الثرايين. الصفائح الدموية تلعب دوا مهما في التسبب في متلازمة الشريان التاجى الصادة عن طريق تشكيل مجمعات الصفائح الدموية.

الهدف من العمل: إظهار العلاقة بين عدد الصفائح الدموية إلى نسبة الخلايا اليمفاوية فى تطوير موت جزء من عضلة القلب المفاجئة

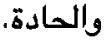

المرضى والوسائل : آجرى البحث على VY مريضا يعانفن من إحتشاء حاد عضلة القلب مع إرتفاع منطقة ST.

النتائج : وقد آظهرت الدراسة آن يوجد علاقة بين عدد الصفائح الدموية إلى عدد الخلايا الليمفاوية في الدم قبل وبعد القسطرة وبين إعادة

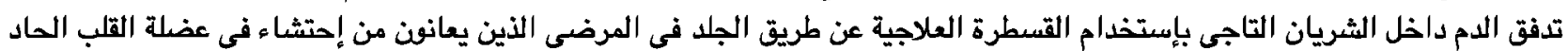

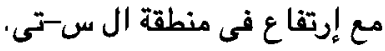

